University of South Florida

DIGITAL COMMONS Digital Commons @ University of @ UNIVERSITY OF SOUTH FLORIDA South Florida

2-1-2015

\title{
Metropolitan Chicago Accessibility Mapping Project
}

CUTR

Follow this and additional works at: https://digitalcommons.usf.edu/cutr_nctr

\section{Recommended Citation}

"Metropolitan Chicago Accessibility Mapping Project," National Center for Transit Research (NCTR) Report No. CUTR-NCTR-RR-2015-12, Center for Urban Transportation Research, University of South Florida, 2015. DOI: https://doi.org/10.5038/CUTR-NCTR-RR-2015-12

Available at: https://scholarcommons.usf.edu/cutr_nctr/36

This Technical Report is brought to you for free and open access by the National Center for Transit Research (NCTR) Archive (2000-2020) at Digital Commons @ University of South Florida. It has been accepted for inclusion in Research Reports by an authorized administrator of Digital Commons @ University of South Florida. For more information, please contact digitalcommons@usf.edu. 


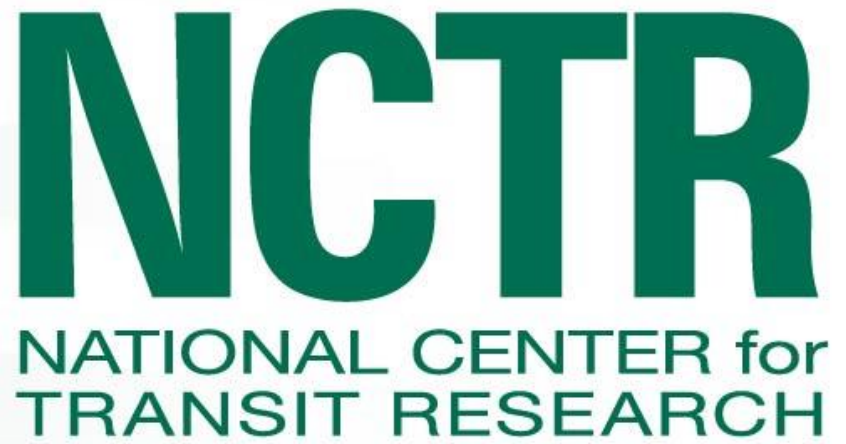

\section{Metropolitan Chicago Accessibility Mapping Project}

Final Report

February 2015

PROJECT NO. 2117-9060-02-C 


\section{Disclaimer}

The contents of this report reflect the views of the authors, who are responsible for the facts and the accuracy of the information presented herein. This document is disseminated under the sponsorship of the Department of Transportation University Transportation Centers Program and the Florida Department of Transportation, in the interest of information exchange. The U.S. Government and the Florida Department of Transportation assume no liability for the contents or use thereof.

The opinions, findings, and conclusions expressed in this publication are those of the authors and not necessarily those of the State of Florida Department of Transportation. 


\section{Metric Conversion}

\begin{tabular}{|c|c|c|c|c|}
\hline SYMBOL & WHEN YOU KNOW & MULTIPLY BY & TO FIND & SYMBOL \\
\hline \multicolumn{5}{|c|}{ LENGTH } \\
\hline in & inches & 25.4 & millimeters & $\mathrm{mm}$ \\
\hline ft. & feet & 0.305 & meters & $\mathrm{m}$ \\
\hline yd. & yards & 0.914 & meters & $\mathrm{m}$ \\
\hline $\mathrm{mi}$ & miles & 1.61 & kilometers & $\mathrm{km}$ \\
\hline \multicolumn{5}{|c|}{ VOLUME } \\
\hline fl. oz. & fluid ounces & 29.57 & milliliters & $\mathrm{mL}$ \\
\hline gal & gallons & 3.785 & liters & $\mathrm{L}$ \\
\hline $\mathrm{ft}^{3}$ & cubic feet & 0.028 & cubic meters & $\mathrm{m}^{3}$ \\
\hline $\mathrm{yd}^{3}$ & cubic yards & 0.765 & cubic meters & $\mathrm{m}^{3}$ \\
\hline \multicolumn{5}{|c|}{ NOTE: volumes greater than $1000 \mathrm{~L}$ shall be shown in $\mathrm{m}^{3}$} \\
\hline \multicolumn{5}{|c|}{ MASS } \\
\hline oz. & ounces & 28.35 & grams & g \\
\hline lb. & pounds & 0.454 & kilograms & $\mathrm{kg}$ \\
\hline $\mathrm{T}$ & Short tons (200o lb.) & 0.907 & $\begin{array}{c}\text { megagrams } \\
\text { (or "metric ton") }\end{array}$ & $\mathrm{Mg}$ (or "t") \\
\hline \multicolumn{5}{|c|}{ TEMPERATURE (exact degrees) } \\
\hline${ }^{\circ} \mathrm{F}$ & Fahrenheit & $\begin{array}{c}5(\mathrm{~F}-32) / 9 \\
\text { or }(\mathrm{F}-32) / 1.8\end{array}$ & Celsius & ${ }^{\circ} \mathrm{C}$ \\
\hline
\end{tabular}




\section{Technical Report Documentation}

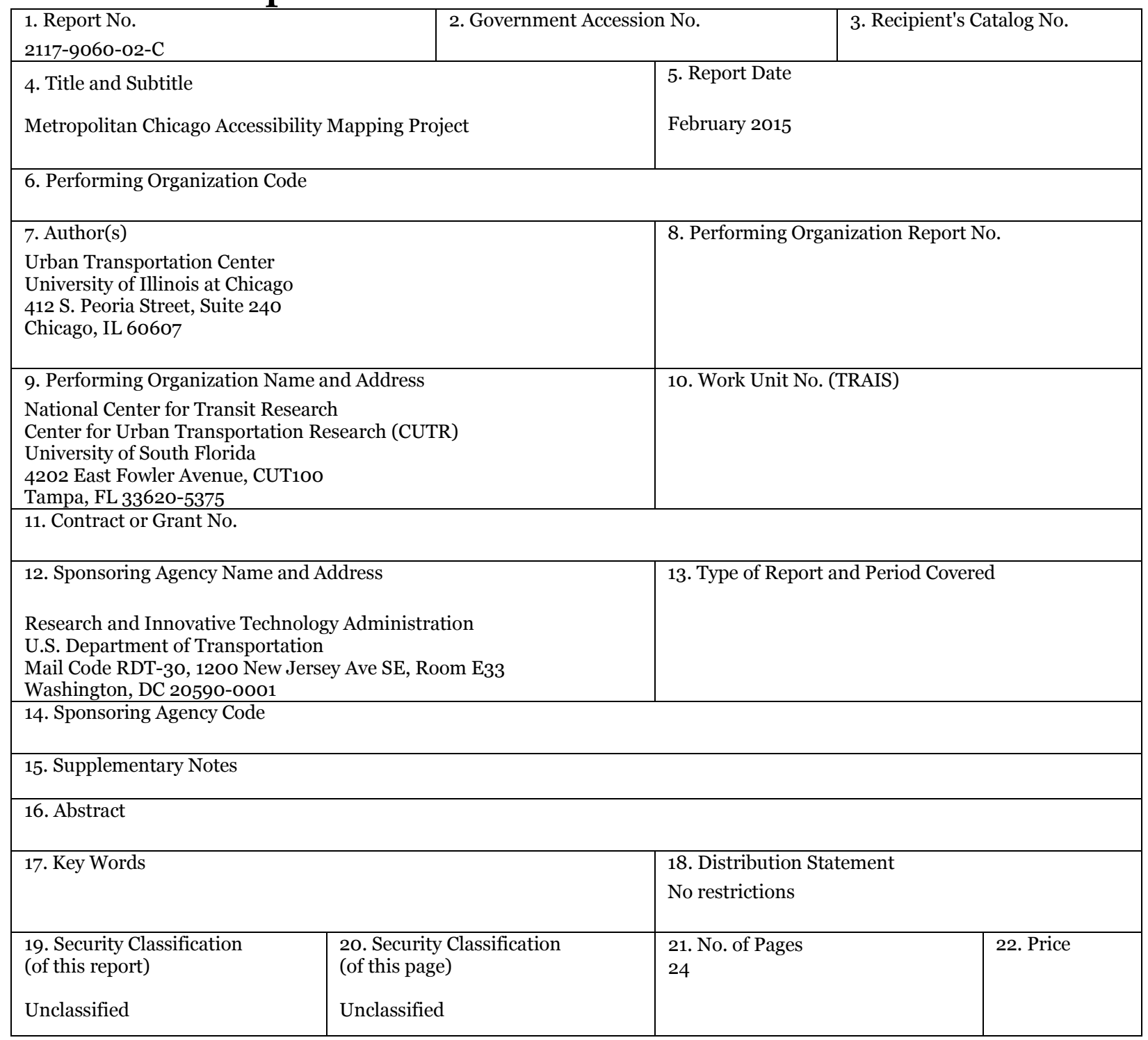




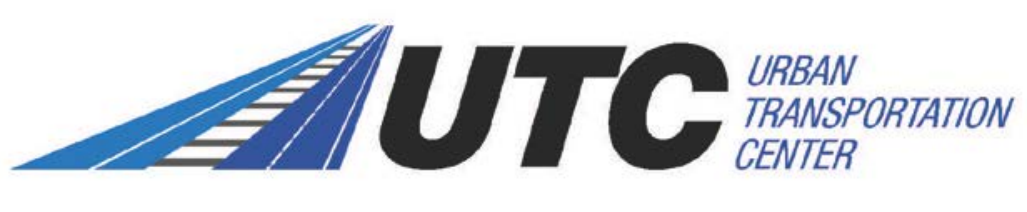

\author{
Urban Transportation Center \\ at the University of Illinois at Chicago
}

\title{
Metropolitan Chicago Accessibility \\ Mapping Project
}

\section{FEBRUARY 2015}

This report was produced with funding from the National Center for Transit Research (NCTR), a US DOT-OST National University Transportation Center.

Metropolitan Transportation Support Initiative (METSI) 


\title{
Metropolitan Chicago Accessibility Mapping Project
}

\author{
Nebiyou Tilahun, Ph.D.* \\ Shi Yin ${ }^{\dagger}$ \\ Moyin $\mathrm{Li}^{\ddagger}$ \\ Yaye Keita $\S$
}

*Assistant Professor, Department of Urban Planning and Policy, University of Illinois at Chicago, 412 South Peoria Street Suite 254, Chicago, IL 60607, ntilahun@uic.edu

${ }^{\dagger}$ Ph.D. Student, Department of Computer Science, University of Illinois at Chicago syin8@uic.edu

${ }^{\ddagger}$ Ph.D. Student, Department of Urban Planning and Policy, University of Illinois at Chicago mli60@uic.edu

${ }^{\S}$ Ph.D. Student, Department of Urban Planning and Policy, University of Illinois at Chicago ykeita2@uic.edu 


\section{Acknowledgment}

This project was funded by the Metropolitan Transportation Support Initiative (METSI) and the National Center for Transit Research (NCTR-USF) through UIC's Urban Transportation Center. We gratefully acknowledge the funders as well as the counties of Cook, DuPage, Kane, Kendall, McHenry, Lake, and Will that shared their data with us. 


\section{Contents}

$\begin{array}{ll}\text { Acknowledgment } & 2\end{array}$

1 Introduction $\quad 4$

2 Methodology 17

3 Data Sources \& Implementation 9

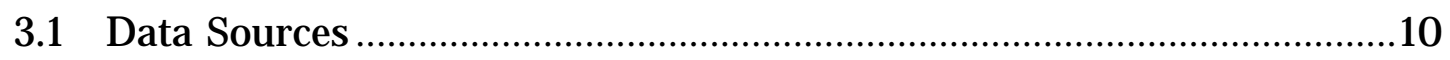

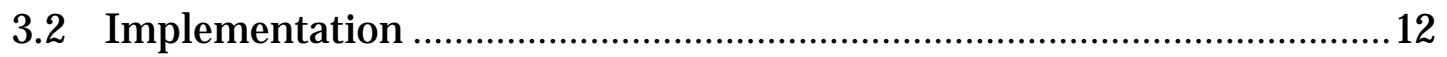

3.3 Rendering Layers ........................................................................................... 13

4 Product 14

5 Future Directions 17 


\section{Introduction}

Accessibility refers to the ease with which one can reach opportunities. It combines measures of mobility and land useand allows us to see what people can get to rather than how far or with what speed they can travel. Though accessibility and mobility are related ideas, they are not synonymous. As Handy (2002) points out, places of high mobility may have low accessibility on account of the built environment and places of high accessibility may havelow mobility on account of substantial congestion. In addition to land use and mobility factors, accessibility measures can also include temporal and individual dimensions as pointed out by Geurs and VAn Wee (2004).

There are various reasons to study accessibility. One is the view that it is not mobility per se that should be the focus of transportation policies but the activities that can be reached. The view of travel as a derived demand is consistent with this view - why travel except for what you are trying to get to? Policy thus should focus on connectingusers to as many opportunities as possiblerather than focusing on the mobility aspects of travel alone. This forces us to think about not just the transportation system, butalso aboutland useand howthetwo workin tandem (see for example, Tilahun and Fan (2014) for an application).

There are also other important reasons for studying accessibility. Several authors have looked at accessibility and labor market outcomes and found a connection, particularly for lower income households. Though evidence is mixed, many have found some aspects of accessibility to be related with employment outcomes (e.g. Sanchez (1998); Thakuriah and Metaxatos (2000); Berechman and Paaswell (2001); Kawabata (2003); Ozbayetal.(2006), reduced welfareusage (e.g. Blumenbergand 
Ong (1998)), differences in employment rates (e.g. Ihlanfeldt and Sjoquist (1990); Ihlanfeldt(2006)), aswell as with commuteoutcomes(e.g. Levinson(1998)).

A regional look at accessibility allows us to understand urban areas as experienced by their residents. Questions about what activities can be reached by residents of a specific neighborhood in reasonable time by a given mode; changes to accessibility over the course of a day as transit systems adjust their schedules to demand; the spatial equities (or inequities) of transportation availability; as well as changes to accessibility over time as jobs and residences shift or as transportation networks change and whom these changes impact can all be visualized in ways that are easily understood.

In summarizing the different ways of measuring accessibility, El-Geneidy et al. (2006) identify five methods - the cumulative opportunities measure, the gravity typeaccessibility measure, utility based accessibility measures, constraints based measures, and compositemeasures. Each measureoffersadvantages(and disadvantages). Particularly focusing on the first three, one can see that the cumulative measure is the simplest and has the advantage of being easily interpretable. Thegravity based measure appropriately discounts opportunities that are further away than closer ones with meaningful impedance/ cost measures. The utility based measure has strong theoretical foundations and allows the analyst to attach values to accessibility in a way the other methods don't. As one moves from cumulative measures to others, the intuitive interpretation of the accessibility numbers declines and complexity of the measurement process increases.

Our goal in this project is to provide an online platform that allows users (planners, transportation professionals, policy analysts, etc.) to measure accessibility forthe metropolitan area of Chicago and to present the information in the most easily 
interpretable fashion. Wethus adopt the cumulative opportunities measure as our main tool for the measurement of accessibility. This measure reports counts, area, etc. of differentopportunitiesorlandusesthatcan bereachedfrom everyoriginin the region within some pre-specified travel times (for example, how many manufacturing jobs can you reach within a 30 minutetravel timeof agiven location?). Themeasures are simple and easily understood. They are presented for a range of opportunities (jobs, parks, schools, groceries, etc.), and at different timethresholds (rangingfrom 5 minutes to 60 minutes). For transit systems, accessibility is measured for different times of day, reflecting changes in service. Weighted accessibility measures arealso presented that reflect thelevel of resident car ownership at origins. Thepresentation of the information also allows users to collect data from their location of interest by simply pointing their cursor at it. The goal is to enable a view of accessibility that can be as macro or as detailed as the analyst wishes it to be.

To enable this, a variety of tasks have been undertaken ranging from developing measures of travel timeforall origin destination pairs in themetropolitan region for automobile, transit and walk modes, to collecting data from a variety of agencies about land use, and integrating them using a variety of open source tools that are availablefororganizingas well aspresentingthisinformation. In thenextsection, we will discussthemethodologythatwasfollowedinmoredetail. Section3discussesthe technical detailsofimplementationaswell asthedatasources. Section 4 discussesthe final product. Finally, section 5 presents future plans for the Metropolitan Chicago Accessibility Explorer ${ }^{1}$.

\footnotetext{
'The Metropolitan Chicago Accessibility Explorer can be accessed at http://www. urbanaccessibility.com
} 


\section{Methodology}

There are multiple ways to measure accessibility. In this project, we used a cumulative opportunity measure to calculate different types of accessibility by different travel type. Thecumulativeopportunities measure counts thenumber of opportunities (e.g. jobs) that can be reached in some travel time threshold (e.g. 45 minutes) by a particular mode (e.g. automobile, transit). Accessibility for a given threshold by a particular modecan be calculated as a simple sum of all opportunities in block groups that can be reached within the predesignated time threshold. Mathematically, leavingmodeand threshold indexes for simplicity, this can be written as:

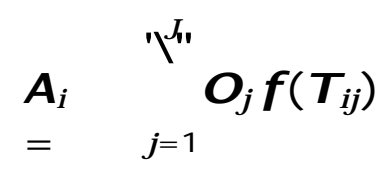

where:

$\boldsymbol{A}_{\mathrm{i}}$ : Accessibility at block group $\boldsymbol{i}$ to activity type $\boldsymbol{O}$ $\boldsymbol{O}_{\mathrm{j}}$ : Opportunities available in block group $\boldsymbol{j}$

$f\left(T_{\mathrm{ij}}\right)$ : A function that takes a value of 1 or 0 based on whether the travel time from $\boldsymbol{i}$ to $\boldsymbol{j}\left(\boldsymbol{T}_{\mathrm{ij}}\right)$ is within a given time threshold ( $1=\mathrm{Yes}, 0=\mathrm{No}$ ).

Once auto and transit accessibility are computed, we also measure accessibility as a composite of these two measures by using vehicle availability to weigh these values. From the perspective of a resident of a block group, the experience of what is accessible is going to depend on what modes are available for them. The compositemeasureapproximates the expected accessibility for a resident of a randomly chosen household. The weighing would pull accessibility levels to that of transitif 
many householdsarecar-less; on theother hand, blockgroups with high percentage of households with cars would have numbers closer to the auto accessibility numbers.

$$
\boldsymbol{A}_{\mathrm{Wi}}=\boldsymbol{A}_{\mathrm{ai}} \cdot \boldsymbol{p}_{\mathrm{i} 1}+\boldsymbol{A}_{\mathrm{ti}} \cdot \boldsymbol{p}_{\mathrm{i} 2}
$$

where:

$\boldsymbol{A}_{\mathrm{Wi}}$ : weighted accessibility for block group $\boldsymbol{i}$

$\boldsymbol{A}_{\mathrm{ai}}$ : auto accessibility for block group $\boldsymbol{i}$

$\boldsymbol{A}_{\mathrm{ti}}$ : transit accessibility for block group $\boldsymbol{i}$

$\boldsymbol{p}_{\mathrm{i1}}$ : percentage of household with at least 1 vehicle in block group $\boldsymbol{i}$

$\boldsymbol{p}_{\mathrm{i} 2}$ : percentage of household with no vehiclesin block group $\boldsymbol{i}$

The percentages for vehicle ownership ( $\boldsymbol{p}_{\mathrm{i} 1} \& \boldsymbol{p}_{\mathrm{i} 2}$ ) come from the 2010 American Community Survey ${ }^{2}$. Since the smallest geography for which data is released is the census tract, weassume that the proportions in a tract apply uniformly to all block groups within in a tract to compute weighted accessibilities.

${ }^{2}$ U.S. Census Bureau; American Community Survey, 2010 ACS 5 year estimates,Table B25044 Tenure By Vehicles Available, generated using American FactFinder December 6, 2014. 


\section{Data Sources \& Implementation}

Multiple data sources were used to calculate the various accessibility types the Accessibility Explorer provides. These include accessibility to jobs in general, jobs by sector, earnings and other classifications, and accessibility to points of interest such as parks, libraries, schools, fire stations, hospitals and grocery stores. These accessibilities are provided at different time thresholds ranging from 5 minutes to 60 minutes separated by different travel modes. Accessibilities are computed for using census block group geographies which provide a fairly detailed resolution to assess howwell connected a location is to different activities or opportunities. Block group definitions correspond to those used in the 2010 decennial census.

Part of the accessibility data - transit accessibility tojobs - came from the University of Minnesota's Accessibility Observatory ${ }^{3}$. The travel time for transit from the Accessibility Observatory was calculated from the centroid of each block group to all blocks in the metropolitan area along a combined pedestrian and transit service network that reflects scheduletimes as published by transit providers in the region ${ }^{4}$. J ob accessibility is computed for Cook, DeKalb, DuPage, Grundy, Kane, Kendall, Lake, McHenry, andWill countiesin Illinois. Automobileaccessibility tojobsas well asautomobile, transit, and pedestrian accessibilitiestotheremainingactivitieswere computed using data sources and processes described below.

\footnotetext{
${ }^{3}$ Accessibility Observatory. http://access . umn. edu. Accessed January 15, 2015

"The pedestrian network is derived from the public OpenStreetMap (OSM) database as of April 16, 2014. It includes all OSM features with the "footway," "pedestrian," and "residential" tags. The transit network is derived from GTFS-format schedules published at metrarail.com, www.chicagotransit.com, and www.pacebus.com. These reflect METRA, CTA, and PACE transit service as of January 2014.
} 


\subsection{Data Sources}

As described in the Methodology section, the inputs to the accessibility matrix are travel times for different modes (in this case block group to block group) and the opportunities orland uses that onewishes to computeaccess to. The data on opportunities/land usescamefromacombination of sources. Thenumber ofjobsbysector data is from the Longitudinal Employer-Household Dynamics (LEHD) $)^{5}$ compiled by the United States Census Bureau. Other land use data besides employment was collected by requestingshapefiles from each metropolitan county's GISDepartment or GIS specialist. We also used the City of Chicago's Data Portal ${ }^{6}$ to collect data specific to the City. Due to data limitations or unavailability, not every type of land use data is available for all counties. A summary of the data availability is shown in Table 1.

Other types of data that were used in the project includenetwork data for the region to compute travel times. These employed Open Street Maps (OSM) ${ }^{7}$ and publicly available General Transit Feed Specification $(\mathrm{GTFS})^{8}$ data for the metropolitan region.

\footnotetext{
${ }^{\mathbf{5}}$ Longitudinal Employer-Household Dynamics. http://lehd.ces.census.gov/data/ Accessed February 1,2015

'City of Chicago's Data Portal. https://data.cityof chicago org Accessed February 1, 2015

'QcOpenStreetMap contributors. http://www . openstreetmap . org Accessed January 15, 2015

${ }^{8}$ GTFS/Scheduled Service Data. http://www.transitchicago.com/developers/gtfs.aspx Accessed January 15, 2015
} 
Table 1: Availability of accessibility type in each county

\begin{tabular}{|l|c|c|c|c|c|c|c|c|}
\hline Accessibility type & City of Chicago & Cook & DuPage & Kane & Kendall & McHenry & Lake & Will \\
\hline Jobs & $\checkmark$ & $\checkmark$ & $\checkmark$ & $\checkmark$ & $\checkmark$ & $\checkmark$ & $\checkmark$ & $\checkmark$ \\
\hline Parks(area) & $\checkmark$ & & & & & & & \\
\hline Parks(count) & $\checkmark$ & $\checkmark$ & $\checkmark$ & $\checkmark$ & $\checkmark$ & $\checkmark$ & $\checkmark$ & $\checkmark$ \\
\hline Libraries & $\checkmark$ & & $\checkmark$ & $\checkmark$ & $\checkmark$ & $\checkmark$ & $\checkmark$ & $\checkmark$ \\
\hline Fire stations & $\checkmark$ & & $\checkmark$ & $\checkmark$ & & $\checkmark$ & $\checkmark$ & $\checkmark$ \\
\hline Schools (all) & $\checkmark$ & $\checkmark$ & & $\checkmark$ & & $\checkmark$ & $\checkmark$ & $\checkmark$ \\
\hline Schools (private) & $\checkmark$ & $\checkmark$ & & & & & & \\
\hline Schools (public) & $\checkmark$ & $\checkmark$ & & & & & & \\
\hline Hospitals & $\checkmark$ & $\checkmark$ & & $\checkmark$ & & $\checkmark$ & $\checkmark$ & $\checkmark$ \\
\hline Grocery stores & $\checkmark$ & & & & & & & $\checkmark$ \\
\hline
\end{tabular}




\subsection{Implementation}

Two tools were used to calculate a Travel Time Matrix (TTM), a customized data structure that behaves like a 2D array, but with customized functionality, in which travel time from each block group to all other block groups in the area is stored. The first tool is the Open Source Routing Machine (OSRM) ${ }^{9}$. OSRM is a highperformance routing engine for shortest paths in road networks written in $\mathrm{C}++$. It is used to calculate the TTMs for automobile travel. OSRM has native support for calculating travel time from a list of origins to a list of destinations. As used here, it was slightly modified to suite our needs.

The second tool we used is OpenTripPlanner (OTP $)^{10}$. OTP is an open source platform for multi-modal and multi-agency trip planning written in J ava. Weused it to produce the TTM for transit. We used a library [otp - jython ${ }^{11}$ to write python scripts to do batch processing via J ava-written OTP.

In summary, theprocessis as follows:

- using OTP, together with OSM data and GTFS data, create a 'Graph'.

- writing python scripts that make use of otp - jy thon to calculateTTMs.

- writingpython scriptstocalculateaccessibility(actual countsofopportunities) based on TTM.

Once accessibility is calculated, it was then converted into geojson layers as follows:

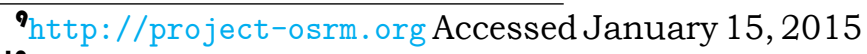

$\mathbf{1 0}_{\mathrm{http}}$ : / /www . opentripplanner. org Accessed January 15, 2014

I'https://github.com/mattwigway/opentripplanner-jython written by Matthew Conway. Accessed January 15, 2015.
} 
- convert accessibility from actual number to percentage (using Python)

- convert them to 'dbf' files (in LibreOffice)

- join our data into shapefile of the area, and change column names (in QGIS)

- convert generated shapefiles to geojson files (using command linetool)

\subsection{Rendering Layers}

The deployment used:

- Leaflet ${ }^{12}$ and Mapbox ${ }^{13}$ for online map service and javascript API.

- Amazon EC2 $2^{14}$ for hosting.

- Flask ${ }^{15}$ as our framework, providing scalability for future expansion.

\footnotetext{
12http://leafletjs.com Accessed January 15, 2015.

${ }^{13}$ https://www.mapbox.com Accessed January 15, 2015.

IAhttp://aws.amazon.com/ec2/ Accessed January 15, 2015.

15 http:/ / flask.pocoo.org Accessed January 15, 2015
} 


\section{Product}

Current implementation of the Metropolitan Chicago Accessibility Explorer is deployed at http://urbanaccessibility. com. Users have the ability to look into different modal or combined accessibility measures for the Metropolitan area depending on data availability on activity locations. A user would first choose what type of accessibility they are interested in looking at. The options include: jobs, parks (by count or area), schools (private, public, both), grocery stores, hospitals, libraries, as well as fire stations. The most expansive coverage is available forjobs while some are limited to the Chicago area only.

Users are allowed to select which travel type they are interested in. Forjobs, three options are available: Auto, Transit and Weighted accessibilities. Auto and transit accessibilitiesrepresent percentage ofjobs thatcan be reached at somechosen travel time threshold. Weighted accessibility accounts for the percentage of households that are car-less (applying the same car-less percentage to each block group as is estimated for the Tract by the American Community Survey. At one extreme, if a block group has a 100\% car ownership, then the auto accessibility is reported. As the percentage of car owners decreases, the accessibility for a block group will be a weighted combination of what can be reached by transit and auto. This represents what theexpectedaccessibilitywouldbeforrandomlychosen householdin theblock group.

Thechoiceof transitpresentsfurtherchoicesto theuser. Transitschedulesand travel times can vary considerably by time of day as operators try to scale operations to demand. As a result, what is reachable in 30 minutes at $8 \mathrm{am}$, for example, may not be reachable at $8 \mathrm{pm}$. Wetherefore offer the user the option to look at time of day 
changestoaccessibilitybyselecting different departuretimes.

J ob accessibility for auto, transit, as well as weighted options areavailableformultipleclasses ofjobs. Onecan selectjobclassesseparated byindustry, correspondingto the 20 two-digit NorthAmerican Industry Classification System (NAICS) classes ${ }^{16}$. In addition, jobs accessibility can be visualized by different demographic characteristics as presented in Work Area Characteristics files presented by the Longitudinal Employer-Household Dynamics (LEHD) data. These categories include age, race, ethnicity, earnings, gender, and educationlevel.

Other accessibilities as currently implemented apply to a smaller geography than for jobs. This is primarily because the data based on which accessibility can be computed has gaps as can be seen from Table 1. For that reason, we have opted to include maps for the City of Chicago, with the goal of updating theaccessibility maps asmorecompletecoveragecan befound.

As currently implemented, the visualization of accessibility uses the J enks natural breaks classification method(J enks, 1967) to cluster blockgroupsinto 7classes, and rendered them using a monochromatic green color scheme. Users are also ableto bring up CTA and Metra lines onto the map for easier reference of location. CTA andMetralinesarealso GeoJ SONfiles converted from shapefiles.

In each of these cases, users interested in measuring accessibility at any given location can hover theirmouseat the point of interest and read theaccessibility for the block group. Theinformation provided includes the percentage of opportunities that can be reached as well as the regional total that percentage is based on. Along with the user providedinputson mode, timethreshold, activity type, thisinformation allows

\footnotetext{
${ }^{16}$ See http://Www.census.gov/cgi-bin/sssd/naics/naicsrch?chart=2012 for these classes.
} 
the user to gather information to allow comparativeanalysis of a place for different purposes(e.g.job classes) orfor differentgeographical locations. 


\section{Future Directions}

TheMetropolitanChicagoAccessibility Explorerisprimarilygeared tomakeiteasier touseofaccessibilityin makingdecisionsabouttransport orland userelated change. Initscurrentform, it enables oneto perform acomparativeassessment of howwell a placeis connected to opportunities - jobs, schools, groceries, etc. Thenextstepisto allow users to assess potential locations to which they can attractjobs, groceries, or other types of land uses with the goal of increasing accessibility to different areas of the region. This will require, given one knows thelocation they are interested in, the creation of maps that show what areas can be reached in some time threshold. Our goal is to provide an interface that is able to do this in an easy and speedy manner. Second, thecurrent system allows users to manuallylookat particularlocationsand read off accessibility values. In futureiterations, weaim to enableselection (e.g. by drawing polygons) and enableusers to download reports from theinterface that has been created. 


\section{References}

Berechman, J . and R. Paaswell (2001). Accessibility improvements and local employment: an empirical analysis. Journal of transportation and statistics 4(3).

Blumenberg, E. and P. Ong (1998). J ob accessibility and welfare usage: Evidence fromlosangeles. J ournal of Policy Analysis and Management17(4), 639- 657.

El-Geneidy, A. M., D. M. Levinson, and H. County (2006). Access to destinations: Development of accessibility measures. Technical report, Report no. MnDOT 200616.

Geurs, K. T. and B. VAn Wee (2004). Accessibility evaluation of land-use and transport strategies: review and research directions. Journal of Transport geography 12(2), 127-140.

Handy, S. L. (2002). Accessibility-vs. mobility-enhancing strategies for addressing automobiledependencein theus. InstituteofTransportation Studies.

Ihlanfeldt, K. R. (2006). A primer on spatial mismatch within urban labor markets.

Ihlanfeldt, K. R. and D. L. Sjoquist (1990). J ob accessibility and racial differences in youth employment rates. The American economic review, 267- 276.

J enks, G. F. (1967). The data model concept in statistical mapping. International Yearbook ofCartography 7, 186- 190.

Kawabata, M. (2003). J ob access and employment among low-skilled autoless workers in us metropolitan areas. EnvironmentandPlanningA35(9), 1651- 1668.

Levinson, D. M. (1998). Accessibility and thejourney to work. J ournal of Transport Geography 6(1), 11- 21. 
Ozbay, K., D. Ozmen, and J. Berechman (2006). Modeling and analysis of the link between accessibility and employment growth. J ournal of Transportation Engineering132(5), 385- 393.

Sanchez, T. W. (1998). The connection between public transit and employment. In Association of Collegiate School of Planning, Annual Conference, Nov. 4-7.

Thakuriah, P. and P. Metaxatos (2000). Effect of residential location and access to transportation on employment opportunities. Transportation Research Record: Journal of the Transportation Research Board 1726(1), 24- 32.

Tilahun, N. and Y. Fan (2014). Transit and job accessibility: an empirical study of accessto competitiveclustersand regional growth strategiesforenhancingtransit accessibility. TransportPolicy 33, 17- 25. 